\title{
Observing Privilege: Examining Race, Class, and Gender in Health and Human Service Organizations
}

\section{Leslie Collins}

Fisk University

\section{Sandra L. Barnes}

Vanderbilt University

\begin{abstract}
Race, class, and gender dynamics can result in power differentials and discrimination in organizations. Such deleterious effects are particularly troubling for non-profit agencies with diverse employee and community bases and that endeavor to redress social inequality through service and program provision. Foucault $(1975,1980)$ as well as Andersen and Collins's (2007) theories provide a means to conceptualize race, class, and gender as power processes that contribute to the production and maintenance of organizational privilege (unearned benefits and advantages). This study uses bivariate and multivariate analyses and data from five health and human service organizations to assess employee perceptions about dynamics that foster organizational privilege. Modeling results indicate that although organizational position is the most influential indicator in explaining perceptions about participation in decision-making, race is the most important predictor of perceptions about access to learning resources and influential relationships. These results also suggest that formally educated White employees are best positioned to access privilege. Thus, such organizations may be fostering social injustices with detrimental effects for employee culture and the communities they serve.
\end{abstract}

Keywords: social inequity, race, Health and Human Service Organizations, diversity, employees

\section{Introduction}

Increasing numbers of scholars contend that if health and human service organizations (HHSOs) wish to minimize the systems of domination associated with racism, sexism, and classism within the communities they serve, a paradigm shift is required from problem focused, reactive practices to those that promote diversity, empowerment, and justice (Evans, 2005; Evans, Hanlin, \& Prilleltensky, 2007; Foster-Fishman \& Behrens, 2007; Foster-Fishman, Salem, Allen, \& Fahrbach, 2001; Trickett, Watts, \& Dina, 1994). However, making changes to practice and service provisions require organizations to modify internal policies and culture to reflect the aforementioned values. Yet, certain kinds of organizational structures and cultures can be disempowering and limit an organization's ability to enact values that empower employees or 
communities. These structures can create pervasive forms of alienation, isolation, and powerlessness among workers. Therefore, if HHSOs are to promote social justice, significant changes in organizational culture, structure, and practices are necessary that require attention to internal processes and societal power dynamics.

For example, race, class, and gender dynamics have been shown to result in power differentials and discrimination in organizations. Such deleterious effects are particularly troubling for nonprofit agencies with diverse employee and community bases and that focus on social justice. Therefore, organizations must continually attend to external power processes (i.e., societal dynamics that influence ideologies, cultures, values as well as practices to control employees, relationships, and organizations themselves) that influence transformation and diversity efforts. This exploratory study is an examination of how such external processes affect employees' perceptions of their work environment. It moves beyond a traditional investigation of social inequalities (e.g., discrimination and discriminatory practices) to focus on organizational mechanisms associated with privilege. Privilege is defined here as the unearned provision of access to resources experienced by some employees to their benefit, but usually at the expense of others (Johnson, 2006; McIntosh, 1988). We reference several theories about power to examine the following two research questions: Will employee traits such as education, tenure, and role vary by race? Will race, class, gender, and features such as tenure and position, influence employee perceptions about organizational dynamics (e.g., learning opportunities, participation in decision-making, and quality relationships) associated with privilege? Quantitative approaches and survey data for fifty-four employees from five HHSOs offer an opportunity to examine the possible effects of race, class, gender, and organizational factors on employee perceptions about their workplaces. We are specifically interested in the implications of employee views about how the kind and quality of access to organizational resources, decision-making (agency), and relationships may facilitate promotions, higher wages, more authority, and social mobility associated with organizational privilege. In addition to empirically testing factors that have been theoretically linked to privilege and power, this study is important given the implications that internal inequities can have on organizations, their employees, and the communities they serve.

\section{Race, Class, and Gender in Organizations: Privilege and Organizations}

Race, class, and gender are profoundly influential in how health and human services organizations are structured, form identities, make decisions about service delivery, and prioritize work. The most common foci of race, class, and gender in organizational studies are discrimination and discriminatory practices. For example, researchers have: used case studies to determine causes of organizational discrimination (Ostrander, 1999; Scott, 2005); examined employees' discriminatory behaviors (Rospenda, Richman, \& Nawyn, 1998) or attitudes (Bertram, Hall, Fine, \& Weis, 2000; Naughton, 1988); and highlighted and evaluated organizations' efforts to redress or end discriminatory practices (Basham, Donner, Killough, \& Merkmeister-Rozas, 1997; Linnehan \& Konrad, 1999; Wooten \& James, 2004). Yet, critics contend that their analyses do not account for how race, class, or gender-based dynamics may facilitate mobility (Corsun \& Costen, 2001; Ibarra, 1995). They challenge organizational studies to attend to structural/societal forces that perpetuate inequality (Gherardi \& Nicolini, 2001; Gherardi \& Poggio, 2003; Nkomo, 1992; Wooten \& James, 2004) - such as discrimination and privilege. 
Privilege is commonly defined as unearned access to beneficial resources available to some people, but usually at the expense of others. This definition is derived primarily from the work of scholars who study privilege in relationship to power (Harvey, 2000) and social justice (Kimmel \& Ferber, 2010; McIntosh, 2010; Serrano-Garcia \& Bond, 1994; Wise, 2010). They posit that privilege is the culmination of the interactions between three forms of relational power dynamics to decide: (1) who is taken seriously; (2) who receives attention; and (3) who is accountable to whom and for what (Johnson, 2006). Understanding how privilege works becomes increasingly important in HHSOs that serve marginalized communities because their espoused values of justice and care should be reflected in both their work culture and practices. However, discussing and countering privilege becomes difficult in organizations where employees are endowed with benefits based on factors such as education, position, tenure, or work quality-many of which are believed to be entirely merit-based.

Bond $(1999,2007)$ provides an example of how norms and values from the dominant culture become rooted within organizational policies and practices such that White males receive benefits by having access to skill sets and social capital that allow them to access organizational resources and thrive to the exclusion of socially marginalized groups such as women and persons of color. Moreover, "homophily" (McPherson, Smith-Lovin, \& Cook, 2001) and "paths of least resistance" (Johnson, 2006) - the ways that members of dominant social groups reap the benefits of more and qualitatively different relationships by virtue of homogeneity - describe processes that allow privileged groups to acquire employment and advance more easily because employers tend to hire, mentor, and promote people who are most like them because of ease. These studies also suggest that many members of privileged groups receive access to more organizational advantages and benefits without understanding how their privileged status affects their points of entry, positions, and tenure, or how it may accentuate their positive contributions and de-emphasize their mistakes and misdeeds.

The conveyance of organizational privilege can influence one's legitimacy and visibility in the organization and community as well as promotions and higher wages (Kolb, 2007). Specifically, organizations that rely on funding and other resources from private donors often use strategies such as homophily and paths of least resistance to raise funds, gain influential volunteers, or access resources that otherwise may not be available to them. To gain credibility, organizations may also hire Whites for positions that require contact with donors, board members (current and potential), and policymakers with whom they share common characteristics and social standing (e.g., race and class). In the process, they may intentionally and unintentionally perpetuate distorted ideologies associated with race, class, and gender and reinforce notions of white superiority, elitism, and male dominance (Feagin, 2010). Moreover, these mechanisms perpetuate white privilege, class privilege, male privilege, and the marginalization of employees of color and women.

\section{Theoretical Framework: Privilege in Organizations}

Researchers who study organizations contend that employees thrive, develop, and advance in spaces with: nurturing, collaborative, and empowering work environments; effective and efficient communication processes; opportunities to learn, grow, and participate in decisionmaking; and, access to resources (Ashcraft, 2001; Ashcraft \& Allen, 2003; Conger \& Kanungo, 1988; Garvin, 2000; Geisler, 2005; Marsick, 1998; Morrison \& Miliken, 2000; Senge, 2006). Therefore, employees who work in such environments tend to have longer tenure, experience 
organizational advancement, earn higher salaries, gain more authority, and experience more social mobility. Thus, employees who experience such positive work environments will be best positioned to also experience privilege. Using wide-ranging conceptualizations of power allows for an investigation of how societal power factors (e.g., race, class, and gender) as well as employee work profiles such as organizational position, role, and tenure influence resource distribution (Samuels \& Samuels, 2003); access to knowledge (Serrano-Garcia, 1994); relationship quality (Bond, 1999, 2007); and, employee perceptions of agency and vice versa. This analysis examines employee perceptions about their work environments and the factors that influence their access to intangible and tangible forms of organizational privilege.

Foucault's (1975, 1980) theory of power provides a way to conceptualize race, class, and gender as processes that contribute to the production and maintenance of privilege in HHSOs. He described power as a complex, multi-dimensional, multi-leveled process embedded within relationships for a single purpose - control. Other scholars have used Foucault's power theory to construct concrete methods of control and mediums through which power moves to make power processes visible in the larger culture (Collins, 2000; Prilleltensky, 2008). For example, Collins (2000) analyzes mechanisms that societies use to circulate power - structural (e.g., social institutions), disciplinary (e.g., rules and procedures), interpersonal (e.g., relationships), and hegemonic (e.g., ideology, culture, and consciousness). Similarly, Prilleltensky and Nelson's (2002) work offers opportunities to understand multiple vehicles of power and also describes how it manifests among individuals, relationships, and collectives to further specific agendas (e.g., oppression, resistance, and/or liberation). Using their theoretical framework and subsequent analyses provide a concrete means of understanding power dynamics, including privilege, in smaller settings such as HHSOs.

Andersen and Collins (2007) also offer a model to study the impacts of societal structures on individuals as well as how individuals construct identities and interact within organizations to benefit or disempower others. They analyze race, class, and gender as systems of power institutionalized processes that differentially advantage and/or disadvantage individuals and groups. Hence, considering how external power systems such as race, class, and gender manifest in organizational cultures and practices is important to understand and introduces two manifestations of power: deprivation and privilege. Understanding the oppressive consequences of racism, sexism, and elitism is the traditional focus and is important. However, in addition to understanding the consequences, it is important to focus on the process. The examination of processes designed to benefit or allow access to individuals and groups based on factors such as race, class, and gender is vital, yet understudied.

\section{Method}

\section{Data Sites}

Survey participants were employed at one of these five HHSOs in a large southern city: John Snow Foundation, MLK Center, Island Center, Healthy Cities, and Nazareth Center (pseudonyms). All but one of the agencies, the John Snow Foundation, provides direct services to meet community members' basic needs. John Snow Foundation, established in 1922, strives to advance the common good by focusing on providing funds for education, health, and improving community conditions. The foundation employs over 100 people and provides grant funding for the other four agencies. MLK Center is a faith-based organization established in 
1894. Over 50 employees provide food banks, meal services, youth programs, workforce development, and community outreach. Island Center has served teenagers and families for over 40 years. Forty employees provide crisis and residential services, youth leadership training, and counseling services. Healthy Cities is a conglomeration of healthcare centers founded in the 1960s. The staff of 70 provides healthcare, health education, outreach, and advocacy for people with limited or no insurance. Finally, Nazareth Center is a faith-based social service agency that has promoted self-reliance and healthy life choices of community members since 1894 . With over 50 employees, Nazareth Center provides childcare, youth services, adult education, senior services, and community outreach. Because these organizations are reputed to be social justice oriented, it is important to consider whether or not their internal mechanisms foster inequality.

\section{The Sample}

The study is based on a convenience, purposive sample that includes fifty-four $(\mathrm{N}=54)$ of approximately 300 employees from the five HHSOs described above. Surveys were administered online and paper surveys were delivered to each organization to increase accessibility and a diverse pool of respondents. Although we cannot confirm representativeness as is done with randomly collected samples, extensive fieldwork at these five sites by the first writer broadly confirms parallels between the HHSOs' workforce and the sample in terms of distribution of females to males, Blacks and Whites, as well as management and front-line presence. The mixed-format survey consists of 101 questions using a six-point, Likert-type scale as well as multiple-choice and open-ended questions. The questionnaire is designed to measure both external as well as internal organizational practices, processes, and culture-based perceptions about: 1) individual and organizational practices; 2) dimensions of learning organizations; and, 3) empowerment. We focus our analyses on Likert-type questions that measure employees' perceptions about their: ability to participate in decision-making processes within their roles (i.e., agency); ability to access training and other learning opportunities; and, perceptions of how and whether or not their work environments facilitate or hinder collaborative, empowering relationships (Yang, Watkins, \& Marsick, 2004).

Three dimensions of organizational power and privilege were examined. Using factor analysis to construct scales that measure employee perceptions, we compare them based on employee demographics such as race, educational level (i.e., an indicator of class) ${ }^{1}$, and gender as well as tenure, organizational role, and position. Readers should note that our racial categories are consistent with those on the 2000 US Census. However, ethnic groups (e.g., non-White Hispanic/Latino or non-black Hispanic Latino) were not included as selection options on the survey. Of the seven options available, respondents self-selected into three categories: 1) Black/African American, 2) White/Caucasian, and 3) Other. Long-term involvement in the five HHSOs by the first writer suggests that the latter category largely consists of persons of Hispanic/Latino decent. We acknowledge the heterogeneity found in the "Other" category. Because we examined privilege as unearned advantages conveyed upon and accumulated by members of dominant social groups (e.g., Whites, college educated/professionals, males), the current analysis initially focused on the experiences and perspectives of employees who are

1 Scholars who study class and classism such as Smith (2008) call for a more expansive description of class that better captures an individual's location in the established hierarchy. They suggest including factors such as access to social networks via family, residence, tastes and preferences, and educational attainment as well as socioeconomic status as indicators class (Bourdieu, 1998 ; hooks, 2000; Smith, 2008). 
members of these groups. Therefore, the Black and Other groups were combined to form one reference group.

Respondents vary based on race and educational level. However, the sample contains a disproportionate number of female respondents $(n=44)$ as compared to males $(n=10)$. Because the majority of employees in these organizations are female, this sample is reflective of the total population. Respondents' roles and their positions are diverse. Average organizational tenure is four years. However, the greatest number of respondents report working about ten years. The modal category is provided here because the secondary data include tenure in predetermined categories including; 3 months $(n=6), 6$ months $(n=0), 9$ months $(n=6), 1$ year $(n=7), 2$ years $(n=4), 3$ years $(n=6), 5$ years $(n=7), 10$ years $(n=10), 15$ years $(n=6)$, and 20 or more years $(n=3)$. A summary of the sample demographics is presented in Table 1 .

\section{Dependent Variables: Three Domains of Privilege}

The dependent variables are a series of three scales that evaluate employees' perceptions about: their participation in decision-making (agency); collaborative, empowering relationships; and, access to learning resources within HHSOs. All scales were constructed using Principal Access Factoring. Items in each scale were highly correlated ${ }^{2}$. The Agency construct measures employees' perceptions about their ability to be involved and include/exclude others in decisionmaking about organizational practices, policies, and processes. The Relationship construct measures employee beliefs about environmental factors that facilitate or hinder collaboration between employees and within organizations. The seven items that comprise the Relationships scale measure qualities within organizational relationships that may facilitate collaboration and empowerment (Marsick 1998; Yang et al 2004). The Learning Opportunities scale measures employees' beliefs about their abilities and chances to acquire organizational information and skills.

\section{Independent Variables}

Six demographic indicators shown to influence organizational dynamics are used in bivariate and multivariate analyses: race, gender, education level, organizational role, tenure, and organizational position. Because we are attempting to assess privilege of dominant social groups (e.g., White, male, and/or highly educated employees), we use members of historically marginalized groups (e.g., employees of color, those with less formal education broadly defined as class, and females) as reference categories ${ }^{3}$.

\section{Analysis Plan}

Two phases of analyses are performed to investigate employees' perceptions about their agency, access to learning resources, and relationship quality. First, a demographic summary of the respondents is presented in Table 1 using $X^{2}$ tests to assess possible intra-group differences. In phase two, because the dependent variables are continuous level scales, Ordinary Least Squares (OLS) regression modeling is used to estimate employee perceptions for three scales that measure organizational features associated with privilege. Moreover, modeling

2 We included a detailed description of survey items used to construct three privilege scales in Appendix $1 \mathrm{~A}$.

3 We included a detailed description of independent variable coding and construction in Appendix $1 \mathrm{~B}$. 
is used because it enables us to simultaneously consider the possible effects of dichotomous as well as continuous level independent variables on the dependent variables more than other methods such as ANOVA. Nested models are used starting with controls for race (Model 1), then introducing education and gender (Model 2), and finally based on employee tenure, role, and position (Model 3). Modeling results are presented in Tables 2 through 4.

\section{Findings}

\section{Demographic Characteristics of HHSO Employees}

Results in Table 1 indicate that employees of color, or those who identify as Black or Other, comprise a combined $60 \%$ of the sample. Moreover, females comprise $81 \%$ of the sample $(n=44)$. Bivariate findings suggest no racial differences in employee tenure or race and employees' organizational roles. When organizational role is considered, a slight majority of the respondents in direct care roles are employees of color (52\% Black and $4 \%$ Other). Although females of color are the statistical majority, a preponderance of Whites tends to be upper and middle level managers. Specifically, $72 \%$ of Whites hold managerial positions. These numbers are in stark contrast to their counterparts of color, who majorly occupy frontline positions $61 \%$ were Black and $15 \%$ were Other. When education is assessed, employees of color tend to have significantly less formal education than their White counterparts. Specifically, the majority of employees who only have high school diplomas are employees of color (92\%), which is substantially different from White employees (8\%). Furthermore, Chi square analyses illustrate a significant correlation between race and education level $\left(X^{2}=9.48\right)$. Additionally, a significant correlation is apparent between race and organizational position $\left(X^{2}=12.94\right)$; White employees tend to hold the majority of the high organizational positions. Yet, it will be important to examine if and how these demographic features influence employee perceptions when they are considered simultaneously.

\section{Modeling Employee Perceptions about Organizational Privilege}

Agency. Table 2 provides nested OLS model results to assess the influence of the five independent variables on employee perceptions about organizational participation. When race is tested in Model 1, findings show that White employees score considerably higher than employees of color $(b=.64, p<.05)$ suggesting that they believe that that they participate in organizational decision-making to a greater degree than their counterparts of color $\left(R^{2}=.010\right)$. However, when considering education level and gender in Model 2, race becomes insignificant; thus White employee scores are no different from those of employees of color. Furthermore, education is not a predictor of employee perceptions of their participation in decision-making. Males are no more or less likely to score differently than females. Yet, when tenure and position are examined (Model 3), the effect of position is important $(b=.85, p<.01)$ and the model's explanatory power over the baseline test significantly improves $\left(R^{2}=0.29\right)$. Position is the greatest predictor of employee perceptions about participation. Race remains insignificant, suggesting that position provides insight beyond race's initial influence. The results suggest that overall, managerial employees (e.g., upper and middle management) believe that they participate in organizational decisions more than their counterparts in frontline positions. These findings parallel organizational studies (Lichtenstein, Smith, \& Torbert, 1995; Senge, 2006) indicate how organizational leaders wield tremendous power because they make decisions that 
affect employees, the organization, and the community. Moreover, they experience privilege because they can make decisions that forward their organizational agendas.

Table 1

Demographic Characteristics of HHSO Employees

\begin{tabular}{|c|c|c|c|c|c|}
\hline & & Race & & & \\
\hline Employee Traits & $\begin{array}{l}\text { Total } \\
(\mathrm{N}=54)\end{array}$ & $\begin{array}{l}\text { Black } \\
(n=26)\end{array}$ & $\begin{array}{l}\text { Other } \\
(\mathrm{n}=6)\end{array}$ & $\begin{array}{l}\text { White } \\
(n=22)\end{array}$ & $x^{2}$ \\
\hline Gender & & & & & 4.79 \\
\hline Percent of Females & $81 \%(44)$ & $43 \%(23)$ & $11 \%(6)$ & $\begin{array}{l}28 \% \\
(15)\end{array}$ & \\
\hline Percent of Males & $19 \%(10)$ & $6 \%(3)$ & $0 \%(0)$ & $13 \%(7)$ & \\
\hline Tenure & & & & & 5.48 \\
\hline 3 - 9 months & $13 \%(7)$ & $43 \%(3)$ & $0 \%(0)$ & $57 \%(4)$ & \\
\hline $1-4$ years & $38 \%(20)$ & $55 \%(11)$ & $20 \%(4)$ & $25 \%(5)$ & \\
\hline $5-15$ years & $43 \%(23)$ & $43 \%(10)$ & $9 \%(2)$ & $\begin{array}{l}48 \% \\
(11)\end{array}$ & \\
\hline 20 years or above & $6 \%(3)$ & $33 \%(1)$ & $0 \%(0)$ & $67 \%(2)$ & \\
\hline Organizational Role & & & & & 2.43 \\
\hline Administrative & $55 \%(28)$ & $39 \%(11)$ & $18 \%(5)$ & $\begin{array}{l}43 \% \\
(12)\end{array}$ & \\
\hline Direct Care & $45 \%(23)$ & $52 \%(12)$ & $4 \%(1)$ & $\begin{array}{l}44 \% \\
(10)\end{array}$ & \\
\hline Education Level & & & & & $9.48 *$ \\
\hline Percent of Diplomas & $22 \%(12)$ & $75 \%(9)$ & $17 \%(2)$ & $8 \%(1)$ & \\
\hline Percent Undergraduate Degrees & $39 \%(21)$ & $48 \%(10)$ & $14 \%(3)$ & $38 \%(8)$ & \\
\hline Percent Advanced Degrees & $39 \%(21)$ & $33 \%(7)$ & $5 \%(1)$ & $\begin{array}{l}61 \% \\
(13)\end{array}$ & \\
\hline $\begin{array}{l}\text { Organizational Position } \\
\text { Frontline Employees }\end{array}$ & & & & & $12.94 *$ \\
\hline Percent of Direct service & $31 \%(16)$ & $50 \%(8)$ & $19 \%(3)$ & $31 \%(5)$ & \\
\hline Percent of Support Staff & $19 \%(10)$ & $80 \%(8)$ & $10 \%(1)$ & $10 \%(1)$ & \\
\hline Percent Middle Management & $26 \%(13)$ & $31 \%(4)$ & $15 \%(2)$ & $54 \%(7)$ & \\
\hline Percent Upper Management & $23 \%(12)$ & $25 \%(3)$ & $0 \%(0)$ & $75 \%(9)$ & \\
\hline Total (percent) & $(100 \%)$ & $(48 \%)$ & $(11 \%)$ & $(40 \%)$ & \\
\hline
\end{tabular}

Note. Education Level: Diploma $=$ High School and GED; Undergraduate $=$ Associates, BS, and BA degrees; Advanced Degrees=MA, MS, professional degrees (e.g., MD, MSN, JD, MBA) and doctoral degrees.

$* \mathrm{p}<.05, * * \mathrm{p}<.01, * * * \mathrm{p}<.001$ level 
Table 2

Linear Regression Coefficients for Participation Scale

\begin{tabular}{|c|c|c|c|c|c|c|c|}
\hline & \multicolumn{3}{|c|}{$\begin{array}{l}\text { Model } 1 \\
\text { Race Only }\end{array}$} & \multicolumn{3}{|c|}{$\begin{array}{c}\text { Model } 2 \\
\text { Race, Class, and } \\
\text { Gender }\end{array}$} & \multirow{2}{*}{$\frac{\underline{\text { Race, }}}{\text { Tenure }}$} \\
\hline & B & $\begin{array}{l}\text { Std. } \\
\text { error }\end{array}$ & $\beta$ & B & $\begin{array}{l}\text { Std. } \\
\text { error }\end{array}$ & $\beta$ & \\
\hline (Constant) & -.28 & .18 & & $-.42 *$ & .20 & & $-.61 * *$ \\
\hline Race (White $=1$ ) & $.64^{*}$ & .26 & .32 & .43 & .30 & .21 & .22 \\
\hline Education (Advanced Degrees $=1$ ) & & & & .43 & .28 & .22 & .05 \\
\hline Gender $($ Male $=1)$ & & & & .29 & .40 & .11 & .24 \\
\hline Tenure ( 3 months to 20 years) & & & & & & & .01 \\
\hline $\begin{array}{l}\text { Position } \\
\text { (Upper/Middle Management }=1 \text { ) }\end{array}$ & & & & & & & $.85^{* *}$ \\
\hline $\mathrm{R}^{2}$ & & .10 & & & .16 & & \\
\hline
\end{tabular}

Note. $\mathrm{N}=49$ from New SPECs Survey Time 2 (2006). Scores range from (-2.56 to 1.47).

$+\mathrm{p}<.10$ level, $* \mathrm{p}<.05, * * \mathrm{p}<.01, * * * \mathrm{p}<.001$ 
Volume 6, Number 1, Summer 2014

Table 3

Linear Regression Coefficients for Relationships Scale

\begin{tabular}{|c|c|c|c|c|c|c|c|c|c|}
\hline & & $\begin{array}{l}\text { odel } 1 \\
\text { ce Only }\end{array}$ & & Race & $\begin{array}{l}\text { odel } 2 \\
\text { Class, } \\
\text { ender } \\
\end{array}$ & & $\begin{array}{l}\text { Race, } \\
\text { Tenur } \\
\end{array}$ & $\begin{array}{l}\text { lodel } 3 \\
\text { lass, } \mathrm{G} \\
\text { and } \mathrm{Pc} \\
\end{array}$ & $\begin{array}{l}\text { der, } \\
\text { tion } \\
\end{array}$ \\
\hline & B & $\begin{array}{l}\text { Std. } \\
\text { error }\end{array}$ & $\beta$ & B & $\begin{array}{l}\text { Std. } \\
\text { error }\end{array}$ & $\beta$ & B & $\begin{array}{l}\text { Std. } \\
\text { Error }\end{array}$ & $\beta$ \\
\hline Constant & $-.35 *$ & .17 & & $-.39 *$ & .20 & & $-.49+$ & .25 & \\
\hline Race (White $=1$ ) & & & & & & & & & \\
\hline & $.77 * * *$ & .26 & .39 & $.78 * *$ & .30 & .40 & $.78^{*}$ & .31 & .40 \\
\hline Education (Advance & & & & & & & & & \\
\hline Degrees = 1) & & & & .18 & .28 & .09 & .17 & .32 & .09 \\
\hline Gender $($ Male $=1)$ & & & & -.24 & .39 & -.09 & -.26 & .39 & -.10 \\
\hline Tenure ( 3 months $t$ & & & & & & & & & \\
\hline 20 years) & & & & & & & .04 & .07 & .10 \\
\hline $\begin{array}{l}\text { Position } \\
\text { (Upper/Middle } \\
\text { Management = 1) }\end{array}$ & & & & & & & -.03 & .34 & -.01 \\
\hline $\mathrm{R}^{2}$ & & .15 & & & .17 & & & .18 & \\
\hline
\end{tabular}

Note. $\mathrm{N}=48$ respondents from New SPECs Survey Time 2 (2006). Scores range from (-2.25 to 1.64).

$+\mathrm{p}<.10$ level, $* \mathrm{p}<.05, * * \mathrm{p}<.01, * * * \mathrm{p}<.001$. 
Relationships. Table 3 shows the nested modeling results concerning employee perceptions about relational environments. Findings indicate that when controlling for education level, gender, tenure, and position, race is the most important predictor and increases perceptions about privileges. Findings from Model 1 show that when compared to employees of color, White employees tend to score higher on this scale $(b=.77, p<.001)$. Thus, they believe that they engage in collaborative and empowering work relationships to a greater degree than employees of color. Moreover, when educational level and gender are included in Model 2, race continues to be the most important predictor $(b=.78, p<.01)$. Differences in education levels do not result in higher or lower scores. Furthermore, males are no more likely to score differently than their female peers. Finally, when considering employee tenure and position (Model 3), they are not influential. Race is the only variable that significantly influences employee beliefs about organizational relationships $(b=.78, p<.05)$. These findings support existing literature that individuals tend to cultivate relationships with others who have similar characteristics, specifically race (Johnson, 2006; Mele, 2003; McPherson et al., 200; Solomon, 1987). Some White employees may advance because they enjoy work relationships that are nurturing, encouraging, and supportive, which ultimately foster skill development, a sense of belonging, personal efficacy, and promotions. Moreover, these results bolster existing research that members of historically marginalized groups often experience isolation and disempowerment in organizational settings (Bond, 1999, 2007). White employees would generally be expected to experience personal as well as professional benefits. These quantitative findings suggest that they believe that they do.

Learning opportunities. The final set of nested models (Table 4) tests the possible effects of the five independent indicators on employee perceptions about their access to organizational resources that foster learning. Although there is slight fluctuation in coefficients across models, race remains the only significant predictor of employee scores on the learning opportunities scales. For example, Model 1 illustrates that when comparing the scores of employees of color with White employees, the latter group tends to score higher $(b=.65, p<.05)$. However, after adding controls for gender and education in Model 2, the race indicator is only minimally predictive $(\mathrm{b}=.59, \mathrm{p}<.10)$. Thus, White employees continue to believe that they have access to learning opportunities to a greater extent than their counterparts of color, but only minimally so. Lastly, when assessing tenure and position with the demographic variables in Model 3, race continues to have minimal influence on employee scores $(b=.65,<p .10)$ and suggests that, albeit modestly predictive, despite differences in organizational positions and tenure, White employees believe that they have greater access to learning resources than employees of color. These results are consistent with Bond's (1999) contention that societal ideologies about race and gender are embedded within organizational policies and practices to provide members of socially dominant groups such as Whites and men with more access to resources that facilitate their professional advancement.

\section{Discussion}

Bond (2007) contends that societal growth and changes in organizations mandate that agencies pay attention to diversity because "they cannot avoid it...they should not ignore it... approach matters and it is quite simply the right thing to do" (p. 3). Her words become especially true for HHSOs because their missions mandate that they strive to meet the changing needs of diverse community members. Organizations with oppressive internal structures, cultures, and practices 
Volume 6, Number 1, Summer 2014

Table 4

Linear Regression Coefficients for Learning Opportunities Scale

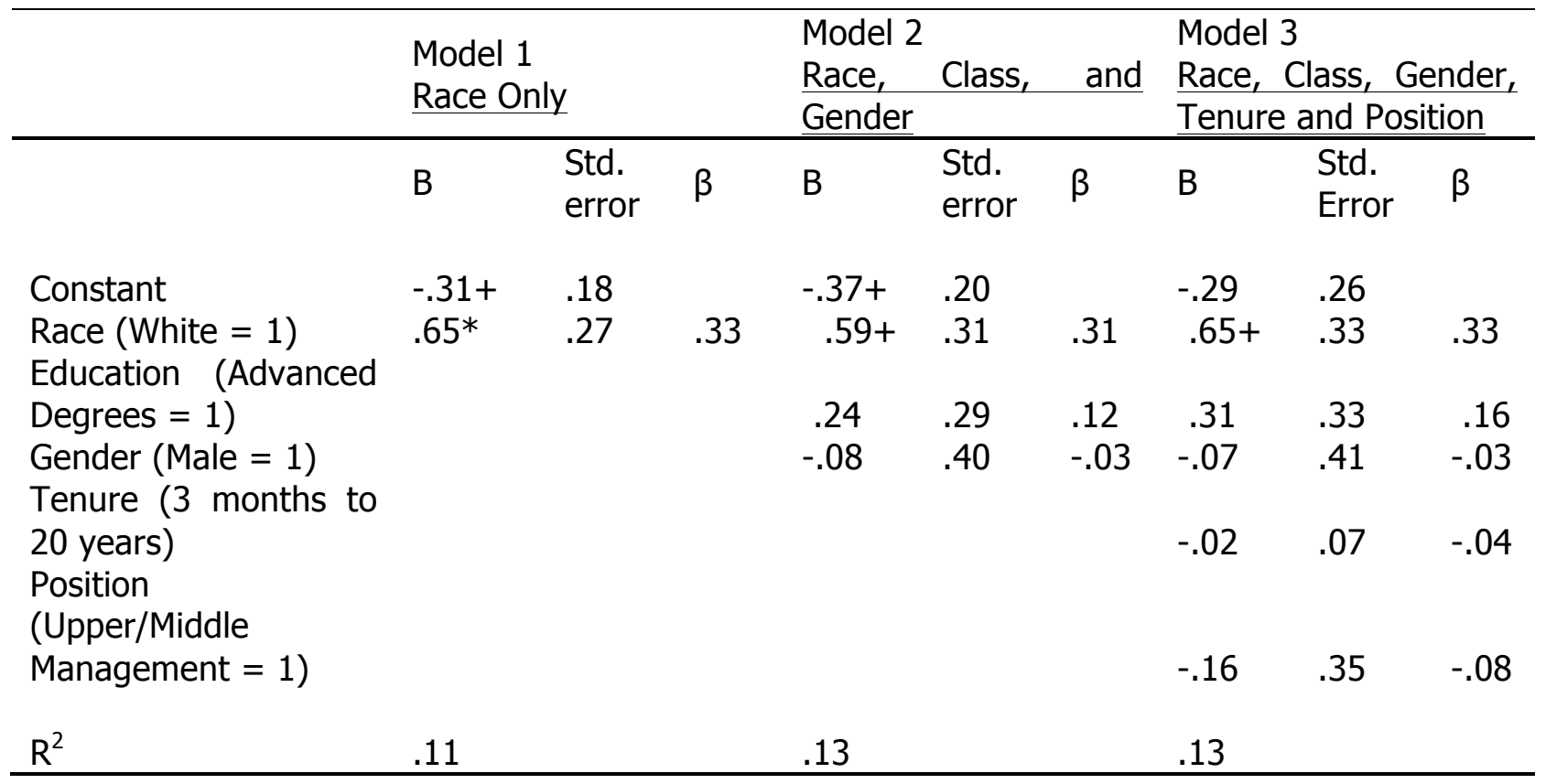

Note: $\mathrm{N}=49$ respondents form New SPECs Survey Time 2 (2006). Scores range from (-2.63 to 1.64). $+\mathrm{p}<.10$ level, $* \mathrm{p}<.05, * * \mathrm{p}<.01, * * * \mathrm{p}<.001$. 
cannot provide services that promote sustainable social justice. Therefore, they must be prepared to reflect just internal cultures and practices by incorporating and integrating the voices of marginalized and oppressed persons (Dei, Karumanchery, \& Karumanchery-Luik, 2005; Freire, 1970).

This study suggests that employees who experience empowering, nurturing, mentoring relationships, participate in constructing organizational policies and practices, can access organizational resources, tend to have longer tenures, experience organizational advancement, make higher salaries, gain more authority, and experience more mobility. Thus, they are conveyed more privilege. Results here show that overall, White employees report more positive experiences of their workspace than their counterparts. Contrary to expectations, class and gender as defined here are not correlated with the factors considered in the current study. Furthermore, although organizational position and role tend to be loosely associated with race, employee tenure is not significantly associated with any of the factors. Yet the bivariate analysis uncovers a relationship between education and race (Table 1 ). White employees tend to have higher levels of formal education and hold higher positions in the organizational structure. Conversely, although women of color comprise the majority of survey respondents, they tend to have considerably less formal education and therefore, hold lower organizational positions, which support Collins's (1997) findings that disparities in educational attainment influences the upward mobility of Blacks in organizations. The results suggest that top-tiered employees believe that they are given more authority and legitimacy by the organizations, co-workers, and communities, and illustrate how organizational privilege manifests based on position (Harvey, 2000; Kolb, 2007).

Multivariate analyses indicate that race is a consistent predictor of perceptions for two of the three scales - relationships and learning opportunities. White respondents tend to believe that their respective organizational environments are conducive to empowering employees and fostering collaboration as compared to employees of color. Moreover, considering race, class, and gender as embedded social forces that normalize values and practices of dominant social groups (i.e., systems of power) can facilitate opportunities for members of the dominant group to access more organizational resources and cultivate more and healthier relationships-thus conveying privilege (Andersen \& Collins, 2007; Collins, 2010). These findings do not confirm that White employees, in fact, have more privilege, nor do they suggest that White employees acknowledge their privilege or that certain advancements may not be merited. However, they suggest that White employees believe that their experiences tend to be more beneficial. Moreover, the aforementioned beliefs about their workspaces could afford them greater position to receive organizational benefits. These results become troubling when considering that employees in higher positions (who are generally White) tend to have greater access to diverse resources; they control the resources of others, they greatly influence policies, and, inform the kind and quality of services provided in their respective communities (Lichtenstein, Smith, \& Torbert, 1995; Senge, 2006). Additionally, employees in the frontline positions, who provide direct service to the community (mostly employees of color), may leave the organization because their access to organizational benefits is limited. Turnover in these positions can hinder the organizations' service provision or halt programs altogether. Thus, the community is negatively affected and social justice efforts are undermined.

Having an expansive understanding of how systems of oppression (e.g., racism, classism, and sexism) manifest and influence individuals, communities, and society is vital to the integrative 
process. Additionally, community members, researchers, practitioners, organizational leaders, and activists must recognize the products of these societal forces (e.g., discrimination and privilege); how they inform organizations at multiple levels; and, how organizations may inadvertently promote these systems internally and reflect them in community practice. If they do not analyze these processes, they will continue to provide services that alienate, silence, and create continual need for services in marginalized communities. Our findings offer an opportunity to examine how organizational cultures, structures, and practices (both internal and external) reproduce and perpetuate societal ideologies that typically propel White employees forward and can stifle efforts toward developing diverse workspaces. Although a largely exploratory endeavor, these findings confirm that using Foucault's (1980) conceptualizations of power, more specifically, Andersen and Collins's (2007) understanding of race, class, and gender as societal power systems provide broad dimensions and a context for examining employees' perceptions of organizational privilege - specifically, access to resources, relationships, and employee agency.

Figure 1 illustrates how race (specifically), class, and gender can influence internal power dynamics, organizational cultures, and enhance or diminish employees' chances for organizational mobility. We elaborate on this framework here as one possible mechanism to better understand organizational privilege and help foster transformations in these spaces. Privilege, like deprivation, is a product of societal power systems. The model centers on three organizational factors: internal power dynamics, employee demographics, and societal (external) forces. Internal power, defined as the processes by which organizations attempt to control individuals and groups, and the processes by which individuals and groups strive to influence those same organizations, manifest in seven primary dimensions - resources, knowledge/learning opportunities, relationships, agency, resistance, leadership, and communication (Collins, 2009).

Societal forces reflect ideologies and values about race, class, and gender that permeate organizations' values, structures, and policies (Clegg, 1989; Clegg, Courpasson, \& Phillips, 2006) as well as historical restrictions to societal resources (such as education) for marginalized groups that influence points of entry into organizations (Collins, 1997). These organizations do not operate in a vacuum. They include employees with pre-developed identities and ideas about their race, class, and gender (as well as other social features) that they use to construct work identities, conceptions about co-workers, and perceptions about the organization. The meanings employees derive inform how they interact with each other and with clients as well as how they understand and link into internal power dynamics. Moreover, employees' tenure, roles, and positions inform how they participate in organizational power processes. We posit that the extent to which employees can engage and experience organizations in positive and productive ways will shape whether and how they become positioned to receive organizational benefits (e.g., upward mobility, increased authority, more access to organizational resources, higher wages, and social mobility). Conversely employees who perceive that they experience organizational inequality will most likely leave, lower their productivity, and/or feel disenfranchised. Such dynamics lead to higher employee turnover and poor service provision the community suffers.

Findings here suggest a more nuanced examination to better understand the intangible and tangible manifestations of privilege in HHSOs. Its insidious nature mandates this kind of inquiry (Fine, Weis, Pruitt, \& Burns, 2004; Johnson, 2006; Kimmel \& Ferber, 2010; McIntosh, 2010). 
This study yields a burgeoning framework that may be adopted, adapted, and tested in applied settings. Its use can broadly enable HHSOs to examine work place dynamics via program evaluations based on the stance that perceived and real intra-organizational inequities undermine effective community service.

Figure 1

The Workings of Organizational Privilege

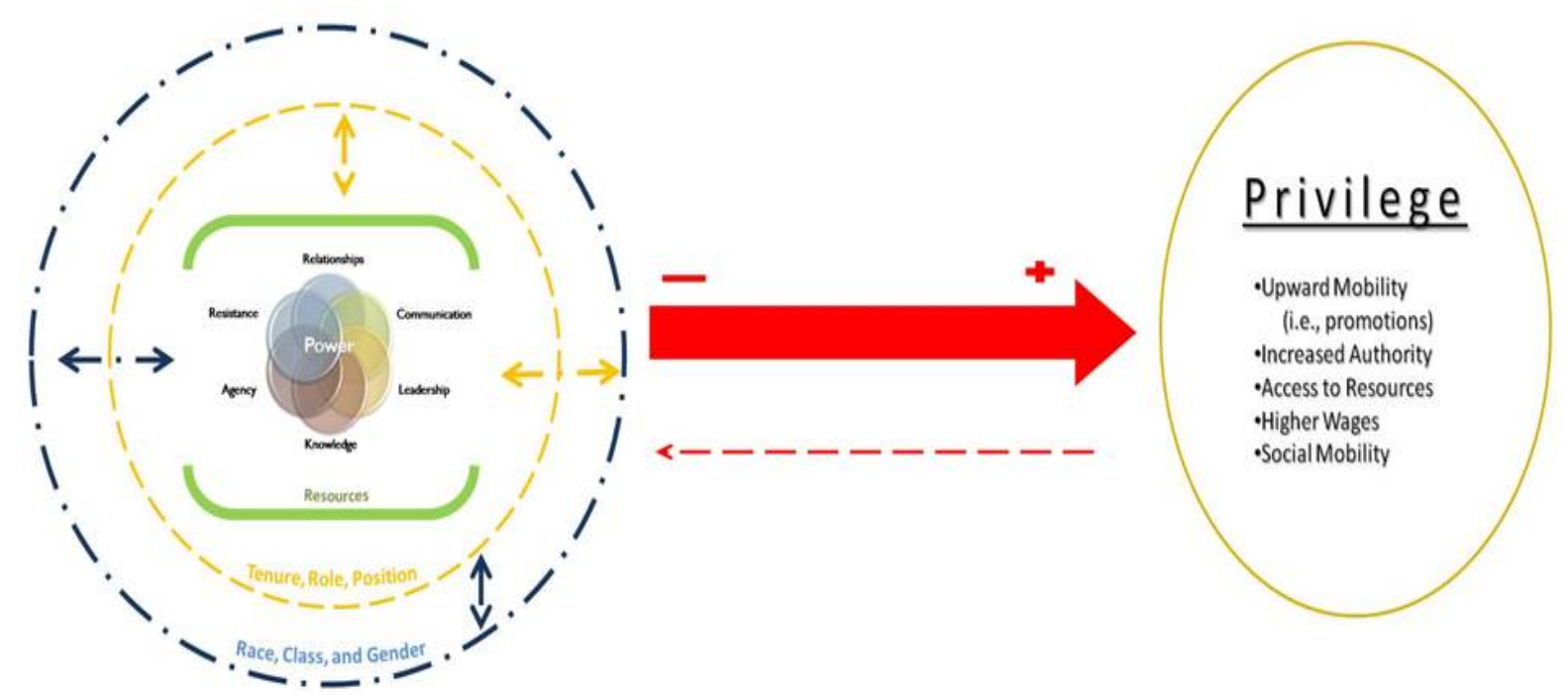

Figure1. This schematic illustrates how societal forces such as race, class, and gender can interact with employee profiles (e.g., tenure, position, and role) to produce organizational privilege. Privileges are the actual products received by employees such as upward mobility, increased authority, and/or higher wages that are largely unearned.

\section{Limitations}

Despite its important implications, this analysis is not without limitations. We contend that intersecting marginalizing identities, similar to oppression, may mitigate the privilege conveyed to individuals. For example, privilege conveyed because of one's "Whiteness" may be muted if one is female (gender) or poor (class). Thus, it is important to acknowledge intra-racial diversity among Whites. However, these findings reflect the salience of race in these organizations' cultures. Furthermore, privilege, like other products of power, is relational. Persons of color comparatively access societal resources by virtue of education or citizenship. Yet the small sample size limited our focus to the perceptions of dominant racial, class, and gender group members separately, which prevents generalizability or tests for interaction effects. Studies based on larger samples that include more males, organizational roles, and variables that identify organizational resources would facilitate investigating intersectionality and how matrices of domination and privilege work in organizational contexts (Collins, 2000; Disch, 2000).

The value of this study lies in its exploratory nature. Our findings provide a unique opportunity to examine employees' beliefs about their work lives and to use these perceptions as a means to operationalize privilege empirically in ways not considered in previous studies. These findings 
suggest that even when other salient indicators are considered, White employees tend to be positioned to experience more organizational privilege. They bolster existing, largely qualitative and anecdotal work on how race, class, and gender can be mechanisms of power that inform organizations' cultures, practices, identities, and relationships (Bond, 1999, 2007; Collins, 2000; Nkomo, 1992). Beyond its academic import, these results provide sobering implications that organizations that purport to emphasize social justice and community service, may be perpetuating some of the very inequalities they endeavor to combat.

\section{Implications for Understanding and/or Ignoring Organizational Privilege}

Studies that make organizational privilege visible are necessary to understand and redress social inequalities (Fine et al., 2004; Kimmel \& Ferber, 2010 Dei et al., 2005; Delgado \& Stefancic, 2001; Freire, 1970; Potts, 2003). Until recently, social justice studies that focused on deprivation were grounded in two assumptions-1) deprivation and privilege were identical dynamics and 2) revealing discrimination in society would reveal privilege. We contend that these assumptions are faulty. In fact, limiting studies on race, class, and gender to focus on discrimination often renders privilege invisible. Critical community practitioners, those anchored in values of social justice, inclusion, self-determination, solidarity, and collective wellness (Nelson \& Prilleltensky, 2002; Prilleltensky, 2001), must become intentional about revealing and dismantling oppressive systems. Critical reflection about how systems maintain and disseminate advantage to dominant groups as well as disadvantage historically marginalized groups is vital to these efforts (Dei et al., 2005; Delgado \& Stefancic, 2001; Freire, 1970; Potts, 2003). This investigation of organizational privilege in HHSOs informs this effort. It may extend the dialogue about social inequalities beyond access and denial of resources to better understand how various aspects of access (e.g., kind, quality, and quantity) facilitate or hinder employees' professional growth, personal wellbeing, and social mobility. Observing privilege within the aforementioned framework reveals the subtle yet persistent ways organizational procedures and policies can reflect and maintain inequities.

How is understanding internal organizational dynamics vital to critical community research and practice? Developing inclusive, cooperative, sustainable models and practices requires that organizations, academics, activists, and leaders engage in careful scrutiny of their philosophies and practices (Conger \& Kanungo, 1988; Dei et al., 2005). Organizations and their leaders that endeavor to engage in anti-oppression work must interrogate social services that are shaped by Eurocentric, middle class, and sexist ideologies and values. Feagin (2010) describes how society embeds hegemony about race in its culture and individual consciousness to construct Whiteness as virtuous, noble, superior, and preferred (i.e. a "White racial frame"). HHSOs may similarly manifest racial, class, and gender frames through policies and procedures and reflect them in practices and programs. Moreover, organizational leaders may invoke these frames to gain legitimacy and credibility with funders and community power brokers; thereby perpetuating injustice (Kolb, 2007). Organizations must also critically reflect on how their cultures foster and perpetuate spaces in which employees remain oblivious to how their social framings and statuses affect interactions with co-workers, clients, and community members through microaggressive behavior - subtle verbal, behavioral, or environmental slights toward marginalized employees that communicate superiority and authority. Micro-aggressions negatively influence co-worker and client relationships, resulting in hostile work environments (Franklin, 1999, 2006; Sue, 2010). 
Fostering community and organizational transformation means asking the following types of questions: Which employee "voices" are legitimated? Whose priorities are adopted and how does that affect organizational structure? Whose knowledge and contributions are valued and how? Whether and how organizations investigate and approach these issues can illustrate their interest level in addressing issues related to privilege and social justice. Our study is intended to reflect on, and step toward answering such questions for substantial organizational and social change. Given the importance of race in this analysis, HHSOs are challenged to avoid merely "placing" representatives from marginalized groups into established, dominant-based structures for the sake of increasing diversity. We contend that HHSOs must engage in the timeconsuming, often arduous process of dismantling such traditional organizational systems and create culturally sensitive spaces that identify, capture, acknowledge, celebrate, and incorporate multiple forms of employees' knowledge, experiences, and values (Poster, 1995).

Observing and combating organizational privilege in HHSOs is crucial for community engagement for the following reasons. First and most poignantly, oppressive organizations (no matter how well intentioned) cannot facilitate just communities. Before they can engage in sustainable community change, their internal dynamics must reflect the values they endeavor to enact (Perkins, et al, 2007). Second, this research provides a catalyst for discussing and dismantling oppressive systems by expanding how society understands some of the effects of racism, classism, and sexism. Truncated conceptualizations and discussions of race, class, and gender have been limited when focusing on redressing deprivation (Kimmel \& Ferber, 2010; West, 1993). Deprivation-focused practices involve developing laws and services that target historically marginalized groups such that they have increased access to material resources (e.g., health care, education, housing, work, or food). However, this practice is insufficient to promote community well-being because interventions are predicated on the assumption that merely "leveling the playing field" will address historical oppression. Yet inequities continue and flourish because dominant groups and institutions control how, whether, and when disenfranchised groups access resources through programs and policies that reflect the former groups' values and experiences. When equity is not achieved, marginalized groups are typically deemed deficient. Thus, deprivation-focused theory, research, and practice enable dominant groups and individuals to relinquish their complicity in receiving, using, and maintaining privilege. Practitioners rarely deconstruct how institutionalized forms of racism, classism, and sexism permeate societies, organizations, communities, and individuals to reinforce White supremacy, male supremacy, and elitism; inevitably silencing diverse voices. We contend that merely acknowledging privilege is insufficient; practitioners must continually deconstruct and confront their complicity in maintaining systems of oppression (Collins, 2000).

Critical reflection within organizations and communities allows organizations, researchers, and practitioners to step back and co-construct theories, frameworks, and practices that incorporate multiple, diverse voices, perspectives, and knowledges. Understanding how deprivation and privilege work to deter their professional and/or personal well-being will provide insight into how these forces affect clients and inform community change efforts. Employees should understand and acknowledge whether and/or how their race, class, and/or gender privilege inform how they authentically interact with clients, empathize with clients, construe client progress, assess client strengths, and assist clients in leveraging strengths to achieve goals. Academic and applied efforts can better influence, equip, and empower employees of HHSOs to realize their goals of social justice inside and outside organizational walls. 
Contact Information:

Leslie Collins

Department of Humanities and Behavioral Sciences

Fisk University

Nashville, TN 37203-5721

Email: lecollins@fisk.edu.

\section{References}

Andersen, M. L., \& Collins, P. H. (2007). Race, Class and Gender: An Anthology (7th ed.). Belmont, California: Wadsworth.

Ashcraft, K. L. (2001). Organized dissonance: Feminist bureaucracy as hybrid form. The Academy of Management Journal, 44(6), 1301-1322.

Ashcraft, K. L., \& Allen, B. J. (2003). The racial foundation of organizational communication. Communication Theory, 13(1), 5-38.

Basham, K. K., Donner, S., Killough, R. M., \& Merkmeister-Rozas, L. (1997). Becoming an antiracist institution. Smith Colleges Studies in Social Work, 67(3), 564-585.

Bertram, C., Hall, J., Fine, M., \& Weis, L. (2000). Where the girls (and women) are. American Journal of Community Psychology, 28(5), 731-755.

Bond, M. A. (1999). Gender, race and class in organizational contexts. American Journal of Community Psychology, 27(3), 327-355.

Bond, M. A. (2007). Workplace Chemistry: Promoting Diversity throgh Organizational Change. London: University Press of New England.

Boulding, K. E. (1989). Three Faces of Power. Newbury Park, CA: Sage.

Bourdieu, P. (1998 ). Practical Reason. Stanford, California: Polity Press.

Clegg, S.-R. (1989). Frameworks of power. In M. Haugaard (Ed.), Power: A reader (pp. 245273). Manchester: Manchester University Press.

Clegg, S.-R., Courpasson, D., \& Phillips, N. (2006). Power and Organizations. London, England: Sage Publications.

Collins, L. V. (2009). Examining Power in Health and Human Service Organizations: A Case Study. (Master of Science Master's thesis), Vanderbilt University, Nashville, TN.

Collins, P. H. (2000). Black Feminist Thought: Knowledge, Conciousness and the Politics of Empowerment (2 ed.). New York: Routledge. 
Collins, P. H. (2010). Toward a new vision: Race, class, and gender as categories of anlysis and connection. In M. S. Kimmel \& A. Ferber (Eds.), Privilege: A Reader (second ed., pp. 233-250). Boulder: Westview Press.

Collins, S. (1997). Black mobility in white corporations: up the coporate ladder but out on a limb. In M. Handel (Ed.), Sociology of Organizations: Classic, Contemporary and Critical Readings (pp. 381-397). Thousand Oaks: Sage Publications.

Conger, J. A., \& Kanungo, R. N. (1988). The empowerment process: Integrating theory and practice. The Academy of Management Journal, 13(3), 471-482.

Corsun, D. J., \& Costen, W. M. (2001). Is the glass ceiling unbreakable?: Habitus, fields and the stalling of women and minorities in management. Journal of Management Inquiry, $10(16), 16-25$.

Crosby, F. J., \& Blake-Beard, S. (2004). Affirmative action: Diversity, Merit and the benefit of white people. In M. Fine, L. Weis, L. P. Pruitt \& A. Burns (Eds.), Off White: Readings on Power, Privilege and Resistance (Second ed., pp. 145-162). London: Routledge.

Dei, G. J. S., Karumanchery, L. L., \& Karumanchery-Luik, N. (2005). Playing the Race Card: Exposing White Power and Privilege. New York, NY: Peter Lang.

Delgado, R., \& Stefancic, J. (2001). Critical Race Theory: An Introduction. New York, NY: New York University Press.

Disch, E. (2000). Reconstructing Gender: A Multicultural Anthonogy (2nd ed.). Mountain View, CA: Mayfield Publishing.

Evans, S. D. (2005). From amelieoration to transformation in human services: Towards critical practice. (PhD Dissertation), Vanderbilt University, Nashville.

Evans, S. D., Hanlin, C. E., \& Prilleltensky, I. (2007). Blending ameliorative and transformative approaches in human service organizations: A case study. Journal of Community Psychology, 35(3), 329-346.

Fadiman, A. (1998). The Spirit Catches You and You Fall Down: A Hmong Child, Her American Doctors and the Collision of Two Cultures. New York, NY: Farrar, Strauss, and Giroux.

Feagin, J. R. (2010). The White Racial Frame: Centuries of Racial Framing and CounterFraming. New York, NY: Routledge.

Fine, M., Weis, L., Pruitt, L. P., \& Burns, A. (2004). Off White: Readings on Power, Privilege and Resistance (Second ed.). London: Routlege.

Foster-Fishman, P., \& Behrens, T. (2007). Systems change reborn: Rethinking our theories, methods and efforts in human services reform and community-based change. American Journal of Community Psychology, 39, 191-196. 
Foster-Fishman, P., Salem, D., Allen, N. A., \& Fahrbach, K. (2001). Facilitating interorganizational collaboration: The contributions of Inerogranizational alliances. American Journal of Community Psychology, 29(6), 875-903.

Foucault, M. (1975). From discipline and punish. In M. Haugaard (Ed.), Power: A Reader (pp. 181-204). Manchester: Manchester University Press.

Foucault, M. (1980). Power/knowledge: Selected Interviews and Other Writings 1972-1977 New York: Parthenon Books.

Franklin, A. (1999). Invisibility syndrome and racial identity development in psychotherapy and counseling african american men. The Counseling Psychologist, 27(6), 761-793.

Franklin, A. (2006). Racism and invisibility: Race-related stress, emotional abuse and psychological trauma for people of color. Journal of Emotional Abuse, 6(2-3), 9-30.

Freire, P. (1970). Pedagogy of the Oppressed. New York: Seabury.

Garvin, D. A. (2000). Learning in Action: A Guide to Putting the Learning Organization to Work. Boston: Harvard Business School Press.

Geisler, D. (2005). The next level in employee empowerment. Quality Progress, 38(6), 48-52.

Gherardi, S., \& Nicolini, D. (2001). The sociological foundation of organizational learning. In M. Dierkes, A. B. Antal, J. Child \& I. Nonaka (Eds.), Handbook of Organizational Learning and Knowledge. Oxford: Oxford University Press.

Gherardi, S., \& Poggio, B. (2003). Creating and recreating gender order in organizations. Journal of World Business, 36(3), 245-259.

Harvey, J. (2000). Social privilege and moral subordination. Journal of Social Philosophy, 31(2), 177-188.

hooks, b. (2000). Where We Stand: Class Matters. New York, NY: Routledge.

Ibarra, H. (1995). Race, oppurtunity and diversity of social circles in managerial networks. The Academy of Management Journal, 38(3), 673-703.

Johnson, A. G. (2006). Privilege, Power, and Difference (Second ed.). Boston: McGraw-Hill.

Kimmel, M. S., \& Ferber, A. (2010). Privilege: A Reader (Second ed.). Boulder, CO: Westview Press.

Kolb, K. H. (2007). Supporting our black men: Reproducing male privilege in a black student political organization. Sociological Perspectives, 27, 257-274.

Lichtenstein, B. M., Smith, B. A., \& Torbert, W. R. (1995). Leadership and ethical development: Balancing light and shadow. Business Ethics Quarterly, 5(1), 96-116. 
Linnehan, F., \& Konrad, A. M. (1999). Diluting diversity: Implications for intergroup inequality in organizations. Journal of Management Inquiry, 8(4), 499-414.

Marsick, V. (1998). Transformative learning form experience in the knowledge era. Daedalus, $127(4), 119-136$

McIntosh, P. (1988). White privilege: unpacking the invisible knapsack. In M. L. Andersen \& P. H. Collins (Eds.), Race, Class, and Gender: An Anthology (7th ed.). Belmont, CA: Wadsworth.

McIntosh, P. (2010). White privilege and male privilege: A personal account of comming to see correspondents through woruk in women's studies. In M. S. Kimmel \& A. Ferber (Eds.), Privlege: A Reader (Second ed., pp. 13-26). Boulder, CO: Westview.

McPherson, M., Smith-Lovin, L., \& Cook, J. M. (2001). Birds of a Feather: Homophily in Social Networks. Annual Review of Sociology, 27, 415-444.

Mele, D. (2003). Organizational humanizing cultures: Do they create social capital? Journal of Business Ethics, 45, 3-14.

Morrison, E. W., \& Miliken, F. J. (2000). Organizational silence: A barrier to change and development in a pluralistic world. The Academy of Management Review, 25(4), 706725.

Naughton, T. J. (1988). Effect of female-linked job titles on job evaluation ratings. Journal of Management 14(4), 567-578.

Nelson, G., \& Prilleltensky, I. (2002). Doing psychology critically: Making a differnce (First ed.). New York: Palgrave/MacMillan.

Nkomo, S. M. (1992). The emperor has no clothes: Rewriting race in organizations. Academy of Management Journal, 17(3), 487-513.

Ostrander, S. (1999). Gender and race in a pro-feminist, progressive, mixed-gendered, mixedrace organization. Gender and Society, 13(5), 628-642.

Perkins, D. D., Bess, K., Cooper, D. G., Jones, D. A., Theresa, \& Speer, P. W. (2007). Community organizational learning: Case studies illustrating a three-dimensional model of levels and order of change. Journal of Community Psychology, 35(3), 303-328.

Potts, R. (2003). Emancipatory education versus school-based prevention in African American communities. [Empirical]. American Journal of Community Psychology, 31(1-2), 173183.

Poster, W. (1995). The challenges and promises of class and racial diversity in the women's movement: A study of two women's organizations. Gender and Society, 9(6), 659-679.

Prilleltensky, I. (2001). Value-Based Praxis in Community Psychology. American Journal of Community Psychology, 29(5), 747-778. 
Prilleltensky, I. (2008). The role of power in wellness, oppression, and liberation: The promise of psychopolitical validity. Journal of Community Psychology, 36(2), 116-136.

Rospenda, K. M., Richman, J. A., \& Nawyn, S. J. (1998). Doing power: The confluence of gender race and class in sexual harrassment. Gender and Society, 12(1), 40-60.

Samuels, S. M., \& Samuels, D. R. (2003). Reconstructing culture: Privilege and change at the United States Air Force Academy. Race, Gender and Class, 10(4), 120-134.

Scott, E. K. (2005). Beyond tokenism: The making of racially diverse feminist organizations. Social Problems, 52(2), 232-254.

Senge, P. (2006). The Fifth Discipline: The Art and Practice of the Learning Organization. New York: Doubleday.

Serrano-Garcia, I. (1994). The ethics of the powerful and the power of ethics. American Journal of Community Psychology, 22(1), 1-20.

Serrano-Garcia, I., \& Bond, M. A. (1994). Empowering the silent ranks: Introduction. American Journal of Community Psychology, 22(4), 433-445.

Smith, L. (2008). Positioning classism within counseling psychology's social justice agenda. The Counseling Psychologist, 36, 895-924. doi: 10.1177/0011000007309861

Solomon, B. B. (1987). Empowerment: Social work in oppressed communities. Journal of Socal Work Practice, 2(4), 79-91.

Sue, D. W. (2010). Microaggressions in Everday Life: Race, Gender, and Sexual Orientation. Hoboken, NJ: John Wiley \& Sons, Inc.

Trickett, E. J., Watts, R. J., \& Dina, B. (1994). Human Diversity. San Francisco, CA: Jossey-Bass Publishers.

West, C. (1993). Race Matters. New York, NY: Vintage Publishing.

Wise, T. (2010). On white pride, reverse racism and other delusions. In M. S. Kimmel \& A. Ferber (Eds.), Privilege: A Reader (Second ed., pp. 133-143). Boulder, CO: Westview Press.

Woods, J. (2010). Black male privileges checklist. In M. S. Kimmel \& A. Ferber (Eds.), Privilege: A Reader (Second ed., pp. 27-37). Boulder, CO: Westview Press.

Wooten, L. P., \& James, E. H. (2004). When firms fail to learn: The perpetuation of discrimination in the workplace. Journal of Management Inquiry, 13(23), 23-33.

Yang, B., Watkins, K. E., \& Marsick, V. J. (2004). The construct of the learning organization: Dimensions, measurment and Validation. Human Resources Development Quarterly, $15(1), 31-5$ 


\section{Appendix 1A. Constructing Dependent Variables (Three Domains of Privilege)}

The Participation scale includes the following five survey items: (1) I have voice and choice in decision-making processes at my organization; (2) I feel I have adequate preparation and skills in order to have a say in decisions; (3) I feel I have enough opportunities in my job to have a say in decisions; (4) I feel I have adequate time to have a say in decisions; and, (5) I have adequate organizational support to have a say in decisions. The items are highly correlated and rotated Principal Axis Factoring (PAF) suggests unidimensionality ( $a=.93$ and eigenvalue = 3.89). Construct scores range from -2.56 to 1.47 where low scores suggest employees believe they have limited participation in making organizational decisions and high scores suggests more participation.

The Relationships scale includes the following seven survey items: (1) my organization considers the impact of decisions on employees; (2) my organization encourages people to get answers across departments; (3) my organization builds alignment of visions across different levels and work groups reversed; (4) in my organization, people give honest feedback; (5) people are rewarded for new ways of working; (6) my organization gives people control of the resources; and, (7) my organization recognizes initiative taking. The items are correlated and a PAF confirms unidimensionality $(a=.95$ and eigenvalue $=5.42)$. Scores range from -2.25 to 1.64. Higher scores suggest that employees believe that their working environments and relationships are collaborative and empowering.

The Learning Opportunities (Resources) scale includes the following six survey items: (1) in my organization, people openly discuss mistakes to learn from them; (2) people view problems in their work as learning opportunities; (3) in my organization, the number of individuals learning new skills is greater; (4) in my organization, investment is skill and professional development is greater; (5) my organization enables people to get needed information at any time; and, (6) leaders generally support requests for learning opportunities. The items are correlated and a rotated PAF confirms unidimensionality $(a=.89$ and eigenvalue $=3.92)$. Scores range from 2.63 to 1.79 where higher scores indicate beliefs that work environments facilitate learning, while lower scores suggest the converse.

\section{Appendix 1B. Constructing Independent Variables}

Six demographic indicators shown to influence organizational dynamics are used in bivariate and multivariate analyses: race, gender, education level, organizational role, tenure, and organizational position. The race variable is divided into two categories; employees of color who identify as Black or Other are coded " 0 " and employees who self-identify as White as coded " 1. " Gender is also a $0-1$ indicator (male=1). Education is divided into two groups. Graduate, professional, and/or doctoral degrees are coded " 1 " and employees who completed basic educational requirements for employment such as a diploma, associates degrees and/or bachelor degrees are coded " 0 ". For organizational role, employees are separated based on functions (i.e., administrative or direct care) and administrative is coded "1". Employee tenure is separated into four categories-employees who have worked for 11 months or less, 1- 4, 5-15, and 20 or more years. Finally, organizational position is divided into two categories; frontline (i.e., direct service and support staff) and managerial (upper and middle management); managerial is coded " 1 ". Because we are attempting to asses privilege of dominant social groups (i.e., White, male, and/or highly educated employees), we use members of historically marginalized groups (i.e., employees of color, those with less formal education broadly defined as class, and females) as reference categories. 